\title{
REPRESENTAÇÕES SOCIAIS COMO CONDICIONANTES DOS PROCESSOS DE DESENVOLVIMENTO TERRITORIAL
}

\author{
Alair Ferreira de Freitas ${ }^{1}$ \\ Alan Ferreira de Freitas ${ }^{2}$
}

\begin{abstract}
RESUMO
Este trabalho objetiva compreender como as representações sociais condicionam os processos de desenvolvimento territorial no Território Serra do Brigadeiro (TSB). As Representações Sociais são utilizadas enquanto aporte teórico e metodológico para auxiliar no entendimento dos sistemas de interpretação que regem nossa relação com o mundo e com os outros, orientando e organizando as condutas e as intervenções na realidade. A partir da realização de entrevistas e de participação em reuniões do colegiado territorial percebemos que no caso do TSB as representações sociais sobre o território, a política pública e os projetos de desenvolvimento condicionaram a interação entre os atores sociais, a sua participação nas dinâmicas locais e ações de intervenção no território. Concluímos que as relações entre atores e deles com os processos instituídos com as políticas púbicas são inerentes às representações sociais que constroem sobre a realidade.
\end{abstract}

Palavras-chave: processos de desenvolvimento, representações sociais, território.

\section{SOCIAL REPRESENTATIONS AS CONDICIONATES OF TERRITORIAL DEVELOPMENT PROCESSES}

\begin{abstract}
This paper aims to understand how the social representations influence territorial development processes in the Serra do Brigadeiro Territory (TSB). The social representations are used as theoretical and methodological support to assist in the understanding of the interpretation systems governing our relationship with the world and with the other, guiding and organizing the ducts and interventions in reality. From conducting interviews and participation in meetings of the collegial we noticed that in the case of territorial TSB social representations on the territory, public policy and development projects affected the interaction between social actors, their participation in the local dynamics and intervention actions in the territory. We conclude that relations between actors and them with the processes established with public policies are inherent to social representations they build about reality.
\end{abstract}

Key words: Development processes, Social Representations, Territory.

\footnotetext{
${ }^{1}$ Graduado em Gestão de Cooperativas (UFV). Mestre em Extensão Rural (UFV). Doutor em Administração (UFMG). Professor do Departamento de Economia Rural (UFV).E-mail: alair.freitas@ufv.br

2 Graduado em Gestão de Cooperativas (UFV). Mestre em Extensão Rural (UFV). Doutorando em Extensão Rural (UFV). Professor do Departamento de Administração (UFV). E-mail: alanf.freitas@ufv.br
} 


\section{INTRODUÇÃO}

O termo território tem ganhado notoriedade na última década, tanto em trabalhos acadêmicos como em políticas públicas, redefinindo o lócus de incidência das intervenções do Estado. A institucionalização dos programas de desenvolvimento territorial rural pelo Ministério do Desenvolvimento Agrário, por exemplo, foi acompanhada de uma intensa efervescência acadêmica sobre o tema, tanto no Brasil como em outros países da América Latina, fomentada principalmente pelo apoio (institucional e financeiro) de organizações multilaterais de promoção do desenvolvimento a partir de meados dos anos 1990. Contudo, uma das críticas mais difundidas a respeito da literatura produzida sobre o tema é que em sua maioria ela possui um caráter normativo, contribuindo pouco para explicar a natureza dos processos que deflagram o desenvolvimento nos territórios rurais criados pelas políticas governamentais (FAVARETO, 2007). Ademais, o território parece estar sendo reificado na maioria das pesquisas, tornando-se uma entidade (às vezes coesa e homogênea), personificada na estrutura de um colegiado territorial.

Um modo de superar tal acepção reificada seria partir de bases explicativas que relativizem a noção de território entendido apenas como um espaço material ou físico ou uma estrutura formal colegiada, que apesar de se constituir como o arranjo organizacional que inicialmente operacionaliza uma política pública, não encerra em si mesmo o processo de desenvolvimento, tão pouco se comporta exatamente como prescrito pelo Estado. A superação desse caráter normativo nos direciona para o uso da noção de representação social como pressuposto teórico-metodológico, buscando compreender porque certos atores tomam determinadas decisões, cooperam ou conflitam entre si e, assim, de maneira geral, para desvelar a natureza dos processos de desenvolvimento nos territórios rurais.

Parte-se da premissa de que as representações sociais moldam as ações dos atores. Nesse sentido, Bourdieu (1996), argumenta que a mudança de representação sobre uma realidade altera, ao mesmo tempo, a forma de ação sobre essa realidade e, consequentemente, muda-se também a própria realidade a partir das intervenções desencadeadas para provocar a mudança. É por isso que as ideias e representações - que se concretizam em discursos e narrativas - são tão importantes.

Tendo em vista a importância (teórica e empírica) de se considerar as representações que os atores sociais envolvidos com essa política possuem sobre o território que ocupam, esse trabalho analisa as representações sociais sobre o Território Serra do Brigadeiro e como essas representações influenciam a implementação de políticas públicas. O objetivo deste artigo é identificar as representações dos atores ligados à política sobre o processo de desenvolvimento territorial e o próprio território Serra do Brigadeiro, buscando compreender como essas representações interferem na trajetória da política pública. Este recorte se justifica por valorizar uma dimensão analítica muito pouco trabalhada nos estudos especializados no tema, desviando o foco do cunho normativo e da política em si, para direcionar o estudo aos atores e suas interações, desvelando uma dimensão cognitiva das interações para o desenvolvimento territorial rural.

Para seguir na direção proposta este artigo está dividido em seis seções, além desta introdução. As próximas duas seções referem-se à ampliação da compreensão do termo território e do seu uso como política de governo. Posteriormente trazemos a noção de representações sociais e sua possível relação com a natureza dos processos de desenvolvimento territorial. Em seguida a 
metodologia delineia os passos dados para a coleta e análise de dados e então são apresentados os resultados e as conclusões.

\section{SIGNIFICADOS E SENTIDOS DA PALAVRA TERRITÓRIO}

De acordo com o dicionário da língua portuguesa, "Território" significa grande extensão de terra, área de um país, de um estado ou de uma cidade, uma porção territorial que está sujeita a uma jurisdição qualquer ou de posse de um animal, pessoa, ou organização. De modo geral, Território é entendido pelo senso comum como uma delimitação geográfica onde se estabelecem contornos de ação para o Estado ou os indivíduos e grupos que lá habitam e dominam.

Porém, o termo território é carregado de significados distintos, que nem de longe se encerram numa delimitação física do espaço. Para Abramovay (2000), que caminha entre a economia e a sociologia, um território significa uma trama de relações com raízes históricas, configurações políticas e identidades que desempenham um papel ainda pouco conhecido no próprio desenvolvimento econômico. Para Haesbaert (2004), que se situa entre a geografia e a antropologia, Território é uma dimensão espacial material das relações sociais e um conjunto de representações sobre o espaço ou o imaginário geográfico que não apenas move, mas integra e é parte indissociável dessas relações.

Até mesmo para as políticas governamentais há diferenças nas delimitações de Território. Para o Ministério do Desenvolvimento Agrário (MDA) o Território é considerado lócus de incidência de políticas públicas, uma referência social espacial para o planejamento do desenvolvimento rural. Para o Ministério da Integração Nacional o Território tem um viés muito mais ligado à organização da base produtiva, focando uma dimensão econômica. É essa definição que baliza e direciona suas políticas publicas. No primeiro caso, Território está vinculado ao rural e tem seu sentido de ação ligado ao fortalecimento de uma categoria social, a agricultura familiar. No segundo, Território está relacionado às relações econômicas, aos arranjos produtivos locais de base empresarial. Essa questão também reforça como veremos adiante, a posição de que as representações direcionam as ações sociais e também as políticas públicas.

Outros sentidos importantes atribuídos pela literatura à categoria "Território" é a noção de Território Dado e Território Construído. Um sentido que liga Território a uma delimitação geográfica para a ação pública e outro que pondera Território como construção social. Independente das congruências e distanciamentos, dos sentidos e significados, Território e a abordagem territorial significam um avanço conceitual e institucional importante para os trabalhos acadêmicos e para as políticas públicas.

\section{A POLÍTICA DE DESENVOLVIMENTO TERRITORIAL}

A adoção da abordagem territorial do desenvolvimento rural define os territórios como lócus de incidência de políticas públicas, redirecionando o planejamento das políticas e as articulações de diversos atores que atuam num dado território. A concepção territorial também carrega uma forma especifica de entendimento sobre os problemas rurais, abordando sua complexidade, introduzindo a noção de melhoria contínua de qualidade de vida do conjunto da população do território (FIALHO; WALQUIL, 2008).

A proposta inicial de um Programa Nacional de Desenvolvimento Sustentável de Territórios Rurais (PRONAT) foi resultado, sobretudo, de reivindicações de setores públicos e de organizações da sociedade civil. Estes atores, em conjunto, baseados em diversas experiências internacionais, 
contribuíram para que os formuladores de políticas públicas percebessem a necessidade de articulação de políticas nacionais com iniciativas que aconteciam no âmbito local (BRASIL, 2003). A proposta de desenvolvimento territorial, coordenada pelo Ministério do Desenvolvimento Agrário (MDA), foi adotada em substituição às políticas dos governos anteriores que tinham o município como seu marco de referência principal, estabelecendo objetivos que consideram a pobreza rural e a dimensão espacial do processo de desenvolvimento como elementos importantes para a formulação de alternativas.

Esta mudança foi particularmente relevante para a extinção da linha Infraestrutura e Serviços do Programa Nacional de Fortalecimento da Agricultura Familiar (Pronaf), que destinava recursos públicos não reembolsáveis para os municípios investirem em projetos de desenvolvimento rural, deixando a cargo dos conselhos municipais de desenvolvimento rural a alocação dos recursos. Com a criação da Secretaria de Desenvolvimento Territorial (SDT) do MDA e a autonomização daquela linha do Pronaf, de responsabilidade dessa secretaria, ocorreram dois movimentos: (i) todos os investimentos de apoio à infraestrutura passaram a ser feitos em agregados de municípios (nos territórios), e (ii) modificouse o marco para a participação social na gestão do programa, exigindo a criação de colegiados territoriais e não mais conselhos municipais (FAVARETO, 2010).

A noção de território desta nova abordagem procura superar o que Brandão (2007), define como "localismo exagerado", buscando definir uma estratégia de desenvolvimento que resulte do enfrentamento de interesses diferenciados e considere a multiescalaridade espacial do desenvolvimento. Tal abordagem seria uma forma de revalorizar as diferentes escalas espaciais na promoção do desenvolvimento, desmistificar a ideia de que o rural se restringe ao agrícola e criar uma interseção entre as dinâmicas socioeconômicas dos espaços rurais e urbanos.

Os territórios criados pelo MDA por meio do PRONAT vieram a ser denominados como "territórios de identidade", partindo do princípio de que a identidade cultural e produtiva é um requisito para a inclusão de um território no programa. Território, na perspectiva da ação pública, é identificado com referência ao zoneamento de determinado problema ou carência da sociedade (territorialização de políticas públicas). Como tal, ele pode se constituir sob uma formalização jurídica, visando precisar sua função dentro da estrutura governamental (BONNAL; CAZELLA; DELGADO, 2012). Apesar de se buscar critérios de identidade entre os municípios, a criação dos territórios é "induzida" pelo Estado para estabelecer uma referência socioespecial para o planejamento de suas políticas públicas.

Uma das características da política de desenvolvimento territorial é que ela privilegia diretamente a participação da sociedade civil na priorização das demandas e na alocação dos recursos públicos destinados aos territórios. A característica endógena da política confere aos atores locais o protagonismo na gestão dos recursos, considerando que isso seja uma condição para a ampliação do sucesso dos investimentos pela adequação dos projetos às reais demandas. Quando se fala em participação da sociedade civil na política de desenvolvimento territorial está se falando em participação das organizações de agricultores familiares, já que outra característica da política é a priorização da agricultura familiar, dos assentados de reforma agrária, quilombolas, dentre outros segmentos sociais rurais de baixa renda, como públicos beneficiários (FIALHO; WAQUIL, 2008).

Da maneira como estabelecido pelo MDA, a formação dos territórios se dá por meio da articulação de atores governamentais e da sociedade civil de um conjunto de municípios, que elaboram uma proposta de constituição destacando potencialidades deste território e os elementos identitários que os unem, e encaminham ao ministério para avaliação. A implementação do programa (PRONAT) 
nos territórios se inicia, após sua aprovação e homologação pelo ministério, com a criação da Comissão de Implementação de Ações Territoriais (CIAT), responsável pela identificação de organizações da sociedade civil e instâncias do poder público que, a partir de sua atuação voltada ao desenvolvimento rural, poderiam compor o Colegiado Territorial. Dentre as atribuições dos colegiados territoriais destacam-se: divulgar as ações do programa, identificar demandas locais, promover a interação entre gestores públicos e conselhos setoriais, contribuir com sugestões para qualificação e integração de ações, sistematizar as contribuições para a elaboração de um Plano Territorial de Desenvolvimento Rural e exercer o controle social do programa (DELGADO; LEITE, 2011).

Diante dos resultados positivos da abordagem territorial por meio do PRONAT, principalmente relacionados à integração de atores da agricultura familiar e de governos locais e a articulação de algumas políticas públicas, além da grande demanda por constituição de territórios, o Governo Federal criou, em 2007, o Programa Territórios da Cidadania, ampliando a abrangência e o volume de recursos do programa anterior, que se manteve em operação. Este programa compôs um conjunto de ações destinadas a reduzir as desigualdades no âmbito da Agenda Social do Governo Federal, propondo ampliar a participação social e garantir a universalização dos programas básicos de cidadania. A representação do Estado foi ampliada, especialmente pelo aumento do número de prefeitos com direito a assento nos colegiados territoriais. A coordenação do programa é do MDA, mas a articulação é feita pela Casa Civil e o monitoramento do programa realizado pelo Núcleo de Estudos Agrários e Desenvolvimento Rural (NEAD).

Com a institucionalização do Programa Territórios da Cidadania o foco para criação dos territórios se expandiu, não apenas priorizando a identidade entre os municípios, mas também a redução das desigualdades e da pobreza nos territórios. Os territórios da cidadania teoricamente são aqueles que possuem os maiores índices de pobreza rural. Alguns dos territórios de identidade foram ampliados e se tornaram territórios da cidadania, sendo regidos a partir de então pelo novo programa. Outros territórios de identidade se mantiveram como tal por não se encontrarem dentro dos índices de referência do novo programa. Mas, de modo geral, o número de territórios rurais induzidos pelo Estado foi ampliado, dando maior destaque à abordagem territorial do desenvolvimento rural no Brasil e despertando ainda mais interesse dos estudos acadêmicos e das críticas neles fundamentados.

Em relação ao grande volume de pesquisas realizadas sobre o tema, Favareto (2007, p. 133), afirma que apesar da profusão de estudos sobre o desenvolvimento rural nos territórios "não há propriamente falando uma teoria do desenvolvimento territorial". Há uma abordagem territorial expressa, sobretudo, no tratamento de um nível específico da realidade e na operacionalização de algumas instâncias empíricas fundamentais. Como afirma o autor, a literatura acadêmica que se constituiu em torno desta abordagem acompanhou a aquiescência do Estado para esta forma de planejamento das políticas públicas e, buscando subsidiá-lo mais do que propriamente compreender as dinâmicas territoriais do desenvolvimento, o que se produziu foi um ideal normativo sobre o desenvolvimento territorial.

Esse ideal normativo construído em torno do desenvolvimento territorial fundamenta-se num conjunto limitado de normas que regulam a constituição dos territórios e o financiamento de projetos, expressos nos documentos normativos instituídos pelo Estado como marco de referência para o funcionamento dos territórios. Segundo Theys (2006), isso repercute em um "caleidoscópio de iniciativas" cuja eficácia é de difícil compreensão. Na prática, vários estudos observam a existência de um processo de justaposição das lógicas territoriais e de hibridação de modelos de construção de territórios em disputa pelos diferentes 
atores que deles se apropriam (BONNAL; CAZELLA; DELGADO, 2012). A variabilidade de configurações adquiridas pelos processos de desenvolvimento rural nos mais diferentes territórios brasileiros sinaliza para a complexidade com que os agentes governamentais precisam lidar na gestão federal dos programas e indica, por exemplo, a possibilidade de se estabelecer uma tipologia de territórios. A territorialização do espaço e das políticas públicas depende das representações que os atores possuem do espaço que vivem e dos arranjos institucionais prevalecentes, da maneira com que os atores interagem entre si e reproduzem as relações de poder.

A pedra de toque do desenvolvimento territorial rural, portanto, não está exatamente na definição de um programa ou como ele está formalizado na estrutura do Governo, mas no território, pensado como uma rede de relações sociais estabelecidas entre diferentes atores e nas estruturas normativas e simbólicas que condicionam os arranjos organizacionais. A configuração destas relações implica numa organização territorial sobre a qual o processo de desenvolvimento se deflagra e, segundo Froehlich e Alves (2007), na definição da identidade espacial que cria a noção de pertencimento ao local. A dinâmica territorial do desenvolvimento é dependente, assim, das representações sociais e da capacidade dos atores em mobilizarem recursos por meio dessa rede a qual passam a pertencer.

Grande parte da literatura que analisa as experiências de desenvolvimento territorial centram-se na análise da "organização" do território como substantivo (organization), mas torna-se preponderante para avançar nas discussões sobre esses processo a perspectiva de "organização" como verbo (organizing). Se as interações (redes e instituições) importam aos processos de desenvolvimento rural (ABRAMOVAY, 2000; 2006, BERDEGUE, 2011, COELHO; FAVARETO, 2008, FAVARETO, 2010), mais que estudar a constituição de instancias formais de gestão dos territórios, espera-se analisar o processo organizativo da qual elas resultam e que as transforma recursivamente (WEICK, 1973).

Esse processo organizativo e de interação é movido, como salientado por Bourdieu (1996), pela representação que atores possuem sobre a realidade, o que molda suas ações. Logo, há um elemento cognitivo que condiciona o processo de organização (organizing) dos territórios. Para Abramovay (2006), esse elemento cognitivo envolve os sentidos atribuídos pelos atores às experiências territoriais, delimitando a porção geográfica e conduzindo diferentes formas de engajamento no território e com outros atores.

Essa questão nos revela como os atores moldam seus comportamentos em conformidade com o que interpretam. Assim, a forma como a realidade é vista, imaginada e representada condiciona os processos de interação e de ação nos territórios, moldando-os, modificando as formas e os conteúdos das ações oriundas das políticas públicas (COELHO; FAVARETO, 2008). Há nesse viés de análise uma dimensão cognitiva do desenvolvimento territorial que só é passível de ser captada e percebida por meio da compreensão de que as representações sociais são norteadoras da ação social. 


\section{AS REPRESENTAÇÕES SOCIAIS COMO ORIENTADORAS DA AÇÃO SOCIAL}

As representações sociais ganharam destaque e relevância na literatura científica, principalmente nas ciências humanas. Este é um conceito cuja dimensão interpretativa ultrapassa os limites de uma única área do conhecimento. Ele é transversal às análises que possuem como foco o comportamento humano e sua constituição como constructo social.

Para Jodelet (2001) frente a um mundo de objetos, pessoas, ideias e acontecimentos em que precisamos nos comunicar e partilhar o nosso mundo, criamos representações sociais. As representações nos servem de apoio, nos direcionam no sentido de nomear e definir os diferentes aspectos da nossa realidade social. As representações também nos guiam nas decisões que tomamos e nas interpretações que fazemos dos fenômenos que nos rodeiam.

Enquanto abordagem teórica metodológica, as representações possibilitam entender os comportamentos coletivos no espaço e no tempo em que são produzidos. É a chamada contextualização histórica, sempre importante à análise sociológica, uma vez que permite identificar símbolos que guiam as ações dos indivíduos no espaço (HOROCHOVSKI, 2004).

Nesse sentido, a teoria das representações sociais se torna um importante instrumento de compreensão e construção social da ação, do conhecimento e das interações sociais. As representações sociais como categoria analítica e instrumento metodológico de pesquisa nos permitem evidenciar as relações estabelecidas entre grupos e entre indivíduos em um determinado grupo, assim como entender a ação dos grupos e dos indivíduos em seus mundos sociais (JODELET, 2001).

Devido a esta capacidade operacional na elucidação de processos de tomada de decisão e de mudança dos rumos da ação e da interação social, o conceito de representação social é trabalhado aqui como categoria interpretativa dos fenômenos que vamos elucidar. Partimos da ideia geral de que as representações conferem um sentido a determinadas práticas e ações, como por exemplo, as mobilizações sociais entorno de causas políticas e as deliberações acerca dos rumos do desenvolvimento do território.

Estas afirmativas estão de acordo com Bourdieu (1996), ao retratar como as representações sociais são responsáveis por determinar o sentido das ações dos atores. Outro fator importante é a delimitação do território por meio da representação do espaço e da identificação com as características da região, ou seja, os atores produzem e delimitam seu espaço de ação de acordo com um repertório de estratégias historicamente constituídas que eles herdam e recriam. Os significados atribuídos pelos atores dão sentido às suas ações e delimitações. Nesse mesmo sentido, tratando das políticas públicas, John (1999) afirma que as políticas representam o resultado de disputas sobre a atribuição de significados e a definição de alternativas de solução aos problemas sociais que buscam enfrentar ou resolver.

As representações são, então, uma forma de imaginar o mundo e agir sobre ele. Quando pensamos o processo de desenvolvimento territorial desencadeado pelas políticas públicas precisamos compreender, sobretudo, a representação que os indivíduos elaboram, porque eles agem e o que querem transformar na realidade. Desta forma, estabelecer a relação entre representações sociais e processos de desenvolvimento é fundamental para entender sua natureza, funcionamento e eficácia.

Foi Durkheim, um dos clássicos da sociologia, o primeiro a elaborar uma teoria social e forjar o conceito de representações coletivas, no início do século XX. A teoria Durkheimiana de representações coletivas está relacionada à ideia de uma dimensão coletiva do conhecimento produzido pelas interações sociais. As 
categorias que norteiam a ação, bem como as diversas práticas sociais, são consideradas representações (ou lógicas), que por sua vez materializam e dão sentido à vida social. Moscovici, apropriando-se da lógica operacional do conceito de Durkheim, inicia o percurso de sua teorização sobre as Representações, chamadas então de Sociais. Esse autor provoca uma renovação das categorias analíticas, insistindo sobre a especificidade dos fenômenos representativos nas sociedades contemporâneas, caracterizadas por: intensidade e fluidez das trocas e comunicações; desenvolvimento da ciência; pluralidade e mobilidade sociais (JODELET, 2001).

Uma das definições mais consensuais no meio acadêmico entre os pesquisadores da área é a de Jodelet (2001, p. 22). Para ela as representações sociais são "uma forma de conhecimento, socialmente elaborada e partilhada, com um objetivo prático, e que contribui para a construção de uma realidade comum a um conjunto social". Em sua definição é explicita a inspiração na noção Durkheimiana, mas principalmente sua filiação teórica à obra de Moscovici.

O conceito de Representações Sociais formulado por Moscovici é inicialmente operacionalizado para trabalhar com o pensamento social em sua dinâmica e em sua diversidade. Parte da premissa de que existem formas diferentes de conhecer e de se comunicar, guiadas por objetivos diferentes, formas que são móveis e que se formam a partir de um repertório de imagens. Duas dessas formas são definidas como: a consensual e a científica, cada uma gerando seu próprio universo (ARRUDA, 2002). A diferença não significa hierarquia nem isolamento entre elas, apenas propósitos diversos. O universo consensual se trata do espaço da vida cotidiana, onde se constitui uma racionalidade comunicativa, enquanto o universo reificado se cristaliza no espaço científico, com seus cânones de linguagem e sua hierarquia interna. Ambas, portanto, "apesar de terem propósitos diferentes, são eficazes e indispensáveis para a vida humana. As representações sociais formam-se mais frequentemente na esfera consensual, embora as duas esferas não sejam totalmente estanques" (ARRUDA, 2002, p. 129).

A introdução das Representações Sociais neste trabalho como aporte teórico e metodológico serve-nos de fato para entendê-las enquanto sistemas de interpretação que regem nossa relação com o mundo e com os outros, orientam e organizam as condutas, as comunicações sociais e os discursos. Portanto, não se trata de uma cópia nem um reflexo, uma imagem fotográfica da realidade; as representações são uma tradução, uma versão, e ao invés de considera-las como fenômeno social à parte da realidade, deve-se atribuir a elas o papel de constituinte do próprio real. De acordo com Jodelet (2001, p. 39), nosso imaginário, ao transmitir uma estrutura imagética da representação se torna guia de leitura e, por generalização funcional, teoria de referência para compreender a realidade, e logo, mecanismo de ação sobre essa realidade.

Para Moscovici (2003), nesta mesma lógica de interpretação que trazemos, as representações são entendidas como entidades "quase tangíveis", presentes na realidade, que se manifestam em palavras e expressões, em produções e consumo de objetos, em relações sociais. Para o autor, as representações correspondem à substância simbólica que entra na elaboração e à prática que produz a dita substância, tal como a ciência ou os mitos correspondem a uma prática científica ou mítica.

Nessa direção, entender as representações sociais como parte da ação dos indivíduos pressupõe-nos desvelar que processos de desenvolvimento e de intervenção na realidade se guiam por "visões de mundo" (GEERTZ, 1989), por elementos simbólicos que constroem modelos mentais de tradução da realidade social. Assim, as representações, como formas de conhecimento e guias para a 
ação social, interferem nos processos de desenvolvimento, diversificando a difusão e assimilação dos conhecimentos, o desenvolvimento individual e coletivo, a definição das identidades pessoais e sociais, a expressão dos grupos expondo as transformações sociais desejadas ou não, bem como os conflitos interpretativos em torno dos conteúdos e significados dos rumos a seguir.

Para Froehlich e Alves (2007) as identidades (e representações) construídas e reconstruídas em torno do território definem padrões de articulação entre os atores. As identidades e os processos cognitivos em torno do planejamento das ações e do espaço são importantes para pensar as diferentes escalas espaciais, definindo de modo simbólico a afiliação e pertença ao território, assim como os rumos do desenvolvimento.

O entendimento dessa relação entre representações sociais e processos de intervenção e de desenvolvimento (territorial) se assenta na noção de modelos mentais elaboradas por Boiser (1999). Para esse autor os modelos mentais são descritos como a pré-figuração racional da ação, são as representações simbólicas de uma realidade percebida ou construída por um ator. Constituem, em parte, o mundo do que é e, em parte, o do que deve ser e sua utilidade prática está em sua possibilidade de conduzir a ação. Na realidade, os modelos mentais devem preceder os modelos reais, e esses últimos devem ser resultado dos primeiros.

Estes elementos derivados da teoria das representações coletivas nos fazem crer que o território, como delimitado nesse trabalho, pode ser mais uma construção mental que uma realidade objetiva. Deste modo, concluímos essa parte teórica com o pressuposto de que a natureza do desenvolvimento territorial é simbólica, o processo se deflagra a partir de representações e disputas por significados e símbolos. Cabe-nos então, afirmar que as representações sociais importam ao objetivo de compreender a ação dos atores nos processos de desenvolvimento territorial.

\section{METODOLOGIA}

Está pesquisa é de natureza qualitativa, assim definida por se considerar um universo de significados, motivos, crenças, valores e atitudes que correspondem a um espaço mais profundo das interações sociais e a processos históricos, os quais não podem ser reduzidos à operacionalização e quantificação de variáveis (TRIVIÑOS, 1987). As pesquisas qualitativas direcionam-se, sobretudo, a descrever a complexidade de determinado problema em seu contexto particular e compreender e classificar processos dinâmicos vividos por grupos sociais.

Quanto ao tipo, esta pesquisa classifica-se como interpretativa. Para Domingues (2004), neste tipo de pesquisa ocorre uma mudança de atenção: dos fatos, como é o caso de pesquisas explicativas causais, à significação, ou seja, ao plano da natureza dos fenômenos. Objetiva-se interpretar as características de determinado fenômeno e os sentidos a ele atribuídos pelos sujeitos, não se restringindo a simples identificação da existência de relações entre variáveis, mas pretendendo também apreender a natureza das relações e suas implicações para o objeto de estudo.

Propõe-se como estratégia de pesquisa o estudo de caso. Segundo Yin (2001), ele é indicado quando o pesquisador lida com condições contextuais, acreditando que elas são de grande relevância para se compreender o fenômeno de estudo. O método de estudo de caso consiste no exame intensivo de um ou mais objetos de estudo, a fim de prover profundidade no entendimento desse objeto, empregando-se variadas técnicas de coleta de dados, com vistas à compreensão das circunstâncias em que eles se encontram e a natureza dos fenômenos que o 
compõem (EISENHARDT, 1989). Assim, o caso é contextualizado e não analisado como uma entidade autônoma. Enfatiza-se a busca pela produção de sentidos, tentando apreender a visão particular dos sujeitos de pesquisa, os sentidos localmente atribuídos.

\subsection{O caso: território Serra do Brigadeiro}

Tendo em vista a aproximação dos pesquisadores com a realidade local do território Serra do Brigadeiro na Zona da Mata de Minas Gerais ${ }^{3}$, e as particularidades de constituição deste território por decorrência das mobilizações em torno da criação e gestão do Parque Estadual da Serra do Brigadeiro, este território foi selecionado para a realização da pesquisa. Ele foi criado no início do programa pelo MDA, e ao longo de cerca de 10 anos de criação recebeu importantes montantes de recursos para aplicação em projetos.

O Território Rural Serra do Brigadeiro (TSB) foi criado em outubro de 2003 pelo Conselho Estadual de Desenvolvimento Rural Sustentável (CEDRS) de Minas Gerais, passando a integrar o PRONAT do MDA. É constituído pelos municípios de Divino, Pedra Bonita, Ervália, Fervedouro, Araponga, Miradouro, Muriaé, Sericita e Rosário da Limeira, como indica a Figura 1 que apresenta as delimitações geográficas do território em questão. O território foi delimitado a partir do Parque Estadual da Serra do Brigadeiro (PESB). O PESB é uma reserva legal de Mata Atlântica que circunda os municípios que compõem o TSB. No mapa apresentado a abaixo vemos os municípios do Território Serra do Brigadeiro, que também abrigam o PESB.

\section{Figura 1 - Mapa do Território Serra do Brigadeiro}

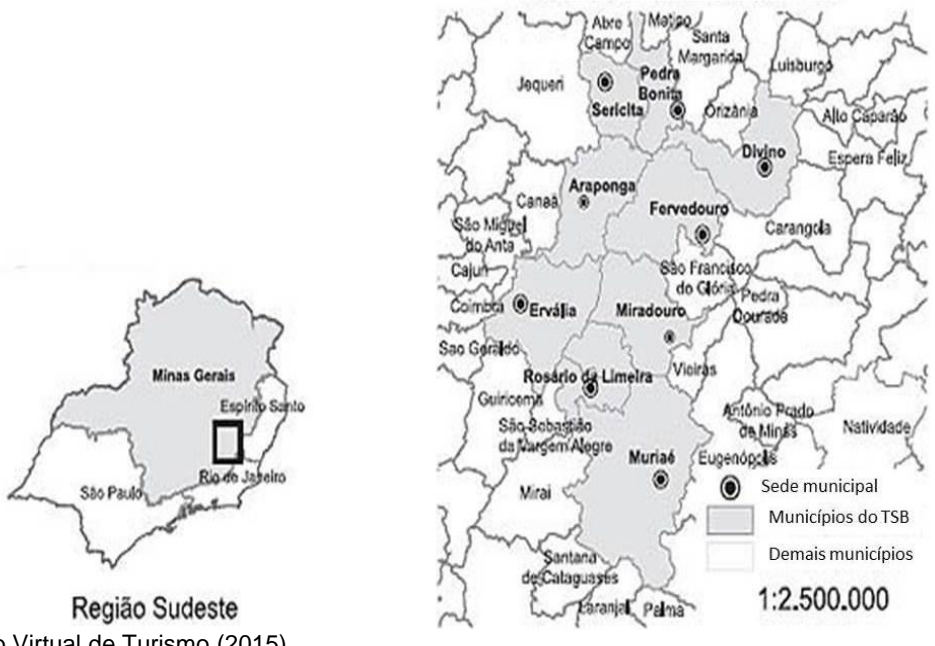

Fonte: Instituto Virtual de Turismo (2015).

Segundo informações contidas no Plano Territorial de Desenvolvimento Rural Sustentável (PTDRS) elaborado no território, a homologação junto ao CEDRS obteve sucesso por algumas características peculiares da região: a identidade

\footnotetext{
${ }^{3} \mathrm{O}$ pesquisador já realizou diversos trabalhos de pesquisa e extensão no território Serra do Brigadeiro e em municípios que o compõem.
} 
cultural, a grande concentração da agricultura familiar nos nove municípios, as articulações e parcerias entre entidades de assistência técnica e as organizações dos agricultores já existentes no território, e por fim o grande patrimônio ambiental do Parque Estadual da Serra do Brigadeiro (PESB). O documento ainda aponta cinco eixos estratégicos para o desenvolvimento sustentável do território: (i) preservação e recuperação do meio ambiente; (ii) Turismo rural; (iii) Agricultura familiar diversificada; (iv) Agroindústria familiar e artesanato; e (v) Cultura. Estes eixos foram definidos no processo de coleta de dados do plano, discutido pelos próprios atores sociais, e por isso se tornam orientadores para a construção dos projetos territoriais (CTA/ZM, 2004).

O TSB surge a partir da mobilização das organizações representativas dos agricultores familiares, iniciada no envolvimento das comunidades locais com a criação do PESB. Os municípios que compõem o TSB são aqueles que circundam esta unidade de conservação ambiental, e as ações políticas iniciais empreendidas pelas organizações governamentais e da sociedade civil para sua constituição resultaram no processo de definição dos limites do TSB e sua homologação pelo Estado.

Por meio da organização formal e informal que se estabelece em função de um objetivo comum é que se arquitetam e se fortalecem as interações sociais na região. E é em função desse processo que a criação do PESB é considerada uma experiência inédita em termos da participação social na criação de uma unidade de conservação, uma vez que a identidade cultural das comunidades da Serra do Brigadeiro e a percepção da importância estratégica do seu patrimônio ambiental, por várias entidades e instituições que atuam na região, foram grandes motivadores de um processo de concertação interinstitucional intenso (CTA-ZM, 2004). A partir dos depoimentos, vemos que o processo de criação do PESB foi um marco na mudança de visão dos atores locais sobre os processos de desenvolvimento na região.

A partir de então, com a criação do TSB, foram constituídas três instancias principais, que auxiliam na gestão das políticas territoriais: o Colegiado de Desenvolvimento Territorial, o Grupo Gestor e a Secretaria Executiva, as quais correspondem respectivamente aos níveis de decisão máxima, decisório gerencial e operacional do território. O colegiado é constituído por três representantes de cada município que compõe o território, sendo um representante do poder público municipal e dois representantes de organizações da sociedade civil, sendo um agricultor ou agricultora e outro do sindicato dos trabalhadores rurais.

O Colegiado funciona como instância deliberativa e de participação. Em sua totalidade o espaço é composto por 38 instituições e representações, nove são representantes dos poderes públicos municipais, quatro de outras instituições públicas, dezoito representantes dos agricultores familiares e sete de organizações da sociedade civil ${ }^{4}$.

Os espaços institucionais de participação do território, principalmente o Colegiado territorial, são constituídos com o objetivo de garantir maior envolvimento de atores locais na discussão sobre a política e na formulação de propostas de projetos para o desenvolvimento territorial. Estes projetos são elaborados à luz das prioridades e necessidades dos agricultores e demais atores, bem como levando em consideração as oportunidades que o território oferece. Eles são aprovados pelo colegiado e a sua execução é feita em conjunto pelas entidades do poder público municipal e as organizações dos agricultores (CTA/ZM, 2004). Tais espaços são as

\footnotetext{
${ }^{4}$ Organizações da sociedade civil que estão sendo representadas no Colegiado Territorial dizem respeito a organizações que atuam junto à agricultura familiar e ao setor agropecuário, chamando atenção às ONGs.
} 
principais referências de articulação entre os atores do território, são onde as decisões são tomadas e onde muitos conflitos são expostos e debatidos. A operacionalização do próprio território se dá nestes espaços, e a partir deles com a execução e monitoramento dos projetos territoriais.

\subsection{Coleta de dados}

A seleção de técnicas de coleta de dados foi alinhada à abordagem qualitativa da pesquisa, por isso priorizou-se aquelas que tenham maior potencial para se apreender as percepções dos sujeitos de pesquisa. Tendo em vista nossos objetivos, define-se como técnicas de coleta de dados a aplicação de entrevista em profundidade com roteiro semiestruturado e a observação não participante.

As entrevistas foram conduzidas a partir de um roteiro semi-estruturado e foram realizadas a partir de agendamento prévio e em local escolhido pelos informantes, que normalmente era no local de trabalho destes. A seleção dos informantes foi feita com os critérios de "acessibilidade" e "exaustão", determinados por Vergara (1998). A acessibilidade refere-se à seleção dos informantes de acordo com as possibilidades de acesso e a exaustão diz respeito ao aparecimento de repetições das informações nas respostas dadas às questões formuladas. Dos 38 representantes do colegiado territorial foram realizadas um total de 12 entrevistas. Além das entrevistas, houve a participação em duas reuniões do CODETER que ocorreram no município de Araponga, nos mês de setembro e outubro de 2014. As anotações sobre as dinâmicas e discursos foram realizadas em caderno de campo. As duas técnicas juntas deram-nos a capacidade de apreender as representações e discorrer sobre a dinâmica estudada.

\subsection{Organização e análise dos dados}

Como técnica de organização e análise dos dados optou-se pela "análise de conteúdo". Para Bardin (2011), a análise de conteúdo pode ser caracterizada como um conjunto de técnicas de análise das comunicações que utiliza procedimentos sistemáticos e objetivos de descrição do conteúdo empírico, os quais permitam inferências sobre as condições de produção de significados e sentidos que os atores sociais exteriorizam no discurso.

A análise de conteúdo foi operada por meio de três etapas subsequentes: i) a pré-análise, ii) a exploração do material, e iii) o tratamento dos resultados, a inferência e a interpretação (BARDIN, 2011). A etapa inicial consistiu na separação e preparação dos materiais que serão analisados (ex: transcrição de entrevistas) e a realização de uma leitura geral para reconhecimento do conteúdo dos dados coletado.

A segunda etapa é essencialmente a codificação do material, processo pelo qual os dados brutos serão alocados em unidades de significação, permitindo o recorte e a descrição das características do conteúdo pertinentes à pesquisa. $A$ codificação envolveu duas etapas: o recorte, que se refere à separação do conteúdo por núcleos de sentido (ou ideias constituintes), e a agregação e classificação, na qual se define a escolha das categorias de análise.

Já a terceira etapa buscou criar as categorias analíticas, dotando os dados de sentido, confrontando-os com o aporte teórico e propondo inferências. De acordo com Bardin (2011, p. 117), "as categorias são rubricas ou classes, as quais reúnem um grupo de elementos sob um título genérico, agrupando esse efectuado em razão dos carcteres comuns destes elementos". A categorização é uma operação de classificação dos núcleos de sentido, que representam elementos constitutivos de 
um conjunto. Para favorecer nossas análises alocamos os dados numa categoria mais geral entendida como "Dinâmica do processo de desenvolvimento Territorial no TSB". Essa opção se deu na intenção de favorecer a compreensão das interações e representações sobre processos específicos que caracterizam a dinâmica no território em estudo. Mais especificamente foi definida como subcategorias a "Delimitação geográfica para a ação", a "Percepção sobre os projetos territoriais" e "O papel do Colegiado".

\section{REPRESENTAÇÕES SOCIAIS COMO CONDICIONANTES DA INTERVENÇÃO DOS ATORES NO TERRITÓRIO}

Refletir sobre a Dinâmica do processo de desenvolvimento territorial no território Serra do Brigadeiro evidenciou a necessidade de se analisar alguns elementos condicionantes da intervenção dos atores, que caracteriza seu engajamento nas ações do território. As diferentes formas e intensidades de engajamento dos atores no processo de desenvolvimento e na operacionalização da política pública mudam ao longo do tempo. A intervenção no território e o engajamento na operacionalização da política são aspectos relacionados individualmente a cada organização, mas estão imbricados diretamente nas interações sociais de que participam seus representantes, são construídos nessa interação.

Esta perspectiva analítica visa a superação do caráter normativo frequentemente encontrado nos trabalhos científicos sobre desenvolvimento territorial. O foco nas interações sociais, reivindicado por Abramovay (2006), pode dotar as análises de aspectos antes pouco observados empiricamente e contribuir para outras formas de compreender o fenômeno. Ao contrário de propor indicações prescritivas de arranjos de sucesso, espera-se aqui discutir os elementos centrais no condicionamento das intervenções no território, o que nos abre possibilidade para a compreensão da maneira como as interações são constantemente atualizadas e como elas criam e recriam dinâmicas específicas de desenvolvimento.

A mudança da natureza dos vínculos entre os atores está muitas vezes associada a uma mudança cognitiva e simbólica, uma mudança de representações sociais, que interfere na maneira como os atores concebem o território e os outros atores e, assim, a forma como intervém no processo de desenvolvimento. A importância disso nessas análises, e que pouco é explicitado nos estudos de desenvolvimento territorial, é destacar como os atores moldam seus comportamentos em conformidade com o que interpretam e, assim, que os sistemas de interpretação da realidade condicionam as interações sociais e são constantemente atualizados por elas. Valoriza-se aqui, portanto, uma dimensão cognitiva na análise do processo de desenvolvimento territorial.

Outra questão que pouco aparece nos estudos especializados, mas de grande relevância para entendimento do fenômeno, é a relação estabelecida entre os atores do TSB e atores e dinâmicas fora do território. Parte-se do pressuposto que as relações extra território lhes fornecem elementos simbólicos, culturais e institucionais que influenciam sua intervenção e relação com o próprio TSB. Sem conhecer esse aspecto da realidade não se compreende o comportamento dos atores e suas intervenções no processo de desenvolvimento. Esse foco reforça a perspectiva de como as dinâmicas de desenvolvimento se constroem a partir de representações e interações sociais que extrapolam a política pública e a região.

A partir de uma dimensão cognitiva da intervenção nos processos de desenvolvimento territorial devemos atentar sobre como os atores significam os relacionamentos de que participam, como mudam esse significado e quais são as 
consequências destas mudanças para a unidade social da qual eles fazem parte. No caso do TSB, a partir dos depoimentos coletados em campo, foi possível perceber, por exemplo, que atores da sociedade civil mudaram suas percepções quando identificaram "ameaça" do poder público. A representação dos atores da agricultura familiar é que os representantes governamentais (de prefeituras) tendem a obter vantagem no processo de seleção de projetos territoriais.

No TSB, como existem dois grupos de sindicatos distintos, a Federação dos Trabalhadores da Agricultura Familiar (FETRAF) e a Federação dos Trabalhadores da Agricultura de Minas Gerais (FETAEMG), os grupos de agricultura familiar viviam em disputa. Mas a mudança de representação sobre o papel das organizações na dinâmica do território, e sobre o sentimento de "ameaça", os grupos resolveram "deixar de lado as divergências políticas para aproveitar as oportunidades de construir um território para a agricultura familiar" (depoimento de representante de sindicato). Essa necessidade de "concorrer" com o poder público e valorizar as organizações da agricultura familiar influenciou o movimento sindical a mudar o significado das relações, a cooperar mais entre si, mesmo sendo de polos diferenciados.

Essas significações são as representações sociais dos atores sobre determinado aspecto da realidade. As representações sociais são guias socialmente construídos que orientam o modo de nomear e definir diferentes aspectos da realidade diária, de interpretar esses aspectos e necessariamente intervir nessa realidade (JODELET, 2001). As representações sociais apoiam-se em valores segundo os grupos sociais de que participam os atores e dos com os quais constroem suas significações da realidade. Para a referida autora, as definições partilhadas pelos membros de um mesmo grupo constroem uma visão partilhada da realidade para esse grupo, em certa medida até consensual. Tal visão se torna, portanto, um guia para as ações e trocas cotidianas entre os atores e, por isso, pode entrar em conflito com a de outros grupos, contribuindo para demarcar posições e oposições no interior de redes de relacionamento.

As representações sociais, assim, podem interferir no comportamento dos representantes das organizações dentro do Colegiado, na continuidade da participação de uma organização e em sua retirada do processo. Os conflitos em si são expressões das representações, sedimentadas por ideologias e valores que levam a uma determinada leitura da realidade e que cria o que a ela é contraditório, definindo oposições frente às dinâmicas engendradas no TSB.

$\mathrm{Na}$ dinâmica do TSB também ficou claro que existem dois grupos da sociedade civil que são divergentes. São duas organizações não governamentais que, sobretudo, disputam recursos, e assessoram grupos de agricultores familiares. Cada organização constrói diferentes representações sobre a realidade e sobre as dinâmicas próprias do território. Estes dois grupos divergentes no TSB, apesar de terem um mesmo público base, de compartilharem de uma mesma história antecessora, após a ruptura do movimento sindical passaram a disputar a legitimidade de representação da agricultura familiar, e representavam um ao outro como adversários, contraditórios e concorrentes, intensificando as disputas internas e reduzindo a possibilidade de cooperação.

Porém, frente aos recursos públicos e à mudança de representação sobre a dinâmica do TSB, assim como nos grupos de sindicatos, se constituiu um "pacto velado" da sociedade civil: os atores, juntos, analisaram a situação e passaram a representar as prefeituras como "inimigas", como concorrentes na captação de recursos e consideraram que as organizações da sociedade civil deveriam se aproximar mais. A representação social compartilhada entre esses atores mudou significativamente a ação no Colegiado, ampliando a coesão da sociedade civil e a 
marginalização das prefeituras, e reduzindo o distanciamento entre os grupos antes divergentes.

Isso também está associado à representação social que os atores criam em relação ao território e à política em si, o que explicita a diferenciação e dificuldades de articulação entre os atores da sociedade civil e do poder público municipal. Apesar dos avanços na aproximação entre eles, isso explica também porque tal avanço não foi mais significativo. Entre os representantes de prefeituras entrevistados, fora aqueles oriundos do movimento sindical, que são minoria no âmbito do TSB, ficou evidente a preocupação em captar recursos financeiros para o município, sendo com frequência mencionados os léxicos "dinheiro", "recursos", "projeto", "desenvolvimento econômico". Uma síntese desta representação é o argumento apresentado por um representante de prefeitura durante uma reunião do Colegiado registrado em diário de campo (2014): "antes era melhor a política né, a gente tinha recurso, via entrar dinheiro no município, mas depois parou, o recurso diminuiu e aí a gente viu que a política foi acabando mesmo, não vemos mais o porquê continuar reunindo. Acabou projeto, acabou território". Essa representação do território como fonte de recursos é, portanto, a mais difundida entre representantes de prefeituras e condiciona o engajamento dessas organizações na política territorial.

Além da representação particularista e municipalista das prefeituras sobre o território e a política, foi possível constatar que para estes atores o território e a política pública são a mesma coisa e ambos se encerram nos recursos federais. Como essa representação condicionava a intervenção desses atores no Colegiado, os outros atores, com histórias e contextos diferentes e, por isso, com representações distintas e contraditórias, criavam sua representação sobre as prefeituras, na maioria das vezes se opondo a elas, como no caso do "pacto velado". A seguir apresenta-se registro das entrevistas que explicitam as representações sociais de representantes da sociedade civil sobre as prefeituras e como elas se comportam ou entendem o território e a política.

Na proposição de projetos, quando tinha recurso os prefeitos ia tudo. Queria só patrol, caminhão, tratores... eles ia tudo. Mas depois sumiram também. Sumiu recurso, sumiu prefeitos (Representante de Organização da Sociedade Civil, 2014).

O problema das prefeituras é que o prefeito quer ser o gestor do projeto e dono do projeto, ele quer aquele bem para ganhar o nome político dele, mas não tem a consciência que se ele descentraliza poder ele ta tirando problema pra ele resolver (Representante de organização da sociedade civil, 2014).

A integração das prefeituras ao colegiado foi mais para captação de recursos mesmo. A gente percebia isso nas falas deles. Queriam recursos pra eles (Representante de organização da sociedade civil, 2014).

Essa representação sobre as prefeituras cria certa aversão dos atores que assim a representam, já que se associa a um projeto contraditório, a um opositor, caracterizando discursivamente as prefeituras, de acordo com as entrevistas, como "inimigas" e "concorrentes". As representações sociais, como sistemas de interpretação, fazem a mediação entre os atores e os contextos em que atuam e com outros atores com quem interagem (JODELET, 2001), por isso assumem papel 
relevante na orientação dos comportamentos, definindo como com que outros atores a interação deverá acontecer.

Mas as representações não são estruturas pré-determinadas às quais os comportamentos obedecem. É na própria interação social que ela se constrói e se atualiza. Foi no âmbito do Colegiado Territorial que muitas prefeituras viram a importância dos sindicatos e das ONGs no desenvolvimento rural e passaram a interpretá-los como organizações com as quais deveriam se relacionar mais, mesmo que com interesses específicos para captação de recursos. Da mesma forma, muitos sindicatos, apesar de perceberem que no PRONAT as prefeituras estavam muito mais preocupadas com recursos do que com o planejamento do desenvolvimento do território, construíra a representação de que elas são atores fundamentais para o processo. Essas representações sociais de ambas as partes contribuíram para o resultado de aproximar poder público e sociedade civil.

Em relação à dinâmica do desenvolvimento no TSB, a mencionada marginalização das prefeituras, é em parte explicada pela representação social de seus representantes de que "não valia mais a pena participar", já que os recursos estavam muito escassos. A falta de recursos financeiros, assim, era um fator de desmotivação, repercutindo na participação desses atores no território. Entretanto, esse movimento na posição das prefeituras está associado também a outra representação social compartilhada entre a maioria dos entrevistados: a centralidade de organizações da sociedade civil e a falta de espaço para os representantes das prefeituras. A interpretação por parte de representantes de prefeituras de que eles estavam sendo excluídos, de que existia uma articulação para afastá-los do processo foi apreendida durante algumas entrevistas, assim como apresentado a seguir.

Existia um Cartel que monopolizava no território. Esses grupinhos internos fechados direcionavam os projetos do território (Representante de organização do setor público, 2014).

Nós das prefeituras, que não éramos dos movimentos já nos sentíamos excluídos. A gente percebia que tinha um cartel lá, dava pra ver. Prefeitura que conseguia êxito eram aquelas que tinham representantes que vieram desse movimento (Representante de organização do setor público, 2014).

Representação nossa tem pouca influência, e os grupos definidos, desanima, não estimula a continuidade da nossa participação (Representante de organização do setor público, 2014).

Segundo Jodelet (2001), as representações sociais são relacionadas ao contexto social em que estão imersas, formadas a partir desse contexto e no âmbito das interações que nele se manifestam, consideradas assim, produtos sociais. Como se percebe, a desmotivação das prefeituras, além da falta de recurso, está também associada à representação social de que esse é um território dominado por outro grupo (opositor) e que as prefeituras têm pouca chance de intervenção nesse contexto. O desestímulo gerado por essa interpretação do contexto, aliado à representação sobre a importância dos recursos, condicionou a continuidade das prefeituras no CODETER, resultando em baixa participação.

A oposição entre organizações da sociedade civil e as prefeituras, entendida a partir das representações sociais, está associada também a como os 
representantes das primeiras interpretam o território e a política e não apenas os outros atores com que interagem nesse contexto. Nas entrevistas com representantes de organizações da sociedade civil os léxicos que com maior frequência representavam o TSB eram "articulação", "investimentos", "território" e "parcerias", denotando dimensões bem diferentes do que encontrado entre os representantes das prefeituras. O território e a política são diferenciados, o primeiro como espaço onde eles vivem e atuam, que permanecerá para além da política, a qual é representada como uma ação do Estado para fortalecer a agricultura familiar, numa perspectiva diferenciada de desenvolvimento. A construção dessas representações define o TSB para além dos recursos financeiros, destacando uma dimensão mais institucional, de legitimidade da agricultura familiar e de ampliação dos contatos e articulações das organizações.

Essa interpretação elaborada pelas organizações da sociedade civil está relacionada à sua trajetória de atuação em articulação com outras organizações, de envolvimento com políticas públicas e relação com o Estado, a partir da qual reconhecem potenciais para além da captação de recursos. Outro elemento é a forma como a organização é conduzida. Os sindicatos e ONGs não mudam significativamente sua política e ideologia com a mudança de diretoria, ao contrário das prefeituras, que em geral passam por mudanças profundas quando se muda o partido político que governa. A continuidade e a ruptura do grupo muda as representações existentes. Os sindicatos em geral se mantêm alinhados à representação acima mencionada. A seguir apresenta-se partes de entrevistas que explicitam as diferenciações de representação entre os atores e reforça as representações diferenciadas de representantes da sociedade civil.

A gente percebe que são os sindicatos $e$ as outras organizações da agricultura familiar que estão mais presentes dentro do colegiado, porque são organizações que estão mais preocupadas diretamente com o desenvolvimento do meio rural. O poder público muita das vezes ficam dentro do território preocupados com projetos, com os recursos que vão para o município. Já as organizações da agricultura familiar sabiam e sabem que o recurso é importante, mas que por trás do recurso tem o interesse das articulações, das parcerias. Até mesmo pela rotatividade das prefeituras né. Muitas vezes as pessoas que entram numa gestão não conseguem acompanhar a política, perdem informação e não dão importância ao território como política. Já as organizações como não tem tanta rotatividade, mantém o compromisso de que o território vai além do recurso, que é pensar uma política de desenvolvimento para a região mesmo. $E$ isso vem de encontro com aquilo que os sindicatos já discutem a muito (Representante de organização do Setor Público oriundo do movimento sindical, 2014).

No poder publico não se fala em desenvolvimento sem se falar em dinheiro. Essa deve ser uma diferença de entendimento que acaba influenciando a continuidade do território. O território, sem recursos, deixa de ser o território para prover o desenvolvimento. Já as organizações compreendem mais a questão da importância das interações entre eles. [...] As organizações da sociedade civil estão interessadas em discutir a política local, não só o acesso a recursos. É discutir os espaços públicos, os investimentos existentes, os conselhos, o fortalecimento político do movimento, porque sabe que 
fortalece a intervenção deles nos espaços (Representante de organização da sociedade civil, 2014).

Essas passagens deixam clara a distinção das representações sociais, uma mais voltada para acesso a recursos financeiros e outra voltada para as articulações e para o fortalecimento da agricultura familiar. Nesse sentido, pode-se constatar que as organizações da sociedade civil interpretam o desenvolvimento como processo, e passam a valorizar projetos de médio e longo prazo e mais complexos; já as prefeituras interpretam o desenvolvimento em termos mais instrumentais, de forma pontual, focando em projetos imediatos, preocupadas menos com o processo e mais com o resultado. Portanto, a forma como representam a realidade, o território e o desenvolvimento interfere diretamente na maneira como intervém nessa realidade, nos tipos de projetos que propõem e nas interações positivas e negativas que constituem.

Estas análises já sinalizam a importância das representações sociais como condicionantes das ações e como elas são modeladas pelas interações sociais. Mas pode-se destacar dos dados coletados outras análises, por exemplo, em relação à Empresa Mineira de Assistência Técnica e Extensão Rural (EMATER) e sua relação com o território e a política. A Emater saiu de uma posição central na dinâmica da política, principalmente após os enfretamentos com uma das organizações da sociedade civil. O representante da Emater, frustrado com a grande resistência que a organização encontrou dentro do colegiado por parte de organizações da sociedade civil, que impunham posições contrárias a ela, passou a interpretar o Colegiado como "lugar de disputa", no qual "a empresa pública não era bem vista" (Representante de organização do setor público, 2014). Isso acabara desmotivando a participação da Emater e promovendo o seu afastamento em relação à política.

Outro exemplo importante do papel das representações sociais na construção do TSB está ligado ao contexto atual de mudança de representante do Centro de Tecnologias Alternativas e descrédito da organização em relação ao território. Além da parada da política ${ }^{5}$, que reduziu os recursos e desmobilizou a organização dos atores, o que gerou uma desmotivação generalizada, o CTA passou por um processo particular que gerou intensos desgastes na organização. A primeira articuladora territorial do TSB, contratada pelo CTA via SDT/MDA entrou com processo na justiça trabalhista contra a organização questionando inadequações do seu vínculo trabalhista e pedindo indenização. Após muitos anos de tramitação do processo, e do esforço do CTA para reverte-lo, a instituição perdeu a causa e teve que pagar uma alta indenização. Esse desgaste e a falta de apoio tanto do MDA, quanto de outras organizações do TSB nessa causa, acabou desmotivando o representante da organização, que passa a representar o território como "passado", "algo que foi bom", como se ele não existisse mais e como "tempo e energia desperdiçados".

Para o representante do CTA, que esteve na representação da organização desde o início, o território não existe mais: "eu tenho uma certa dificuldade de fazer essa representação porque pra mim esse território não existe mais. Eu, pra mim, hoje, no território... eu não consigo fazer uma representação dele, na prática." (Representante de organização da sociedade civil). Mas o CTA não se ausentou do CODETER e nem se afastou da rede do TSB, apenas trocou o seu representante. A manutenção no Colegiado e nas ações desenvolvidas no âmbito da rede são

\footnotetext{
${ }^{5}$ Consideramos "parada na política" o desaquecimento por parte do Estado das mobilizações em torno da política territorial, que ocorreu em função de reformulações dos programas e contingenciamento dos recursos destinados a essas ações.
} 
justificadas pela necessidade de não romper os vínculos já constituídos e pela expectativa de o PRONAT ganhar força na mudança do Governo Federal.

As ponderações até aqui nos mostram que as relações entre atores e deles com os processos instituídos com as políticas são condicionados pelas representações que possuem. Ao mesmo tempo podemos perceber que as representações também se moldam a partir das interações e dos processos vividos. Frente a toda essa dinâmica podemos apontar três últimas questões que fundamentam as análises empíricas: (i) A delimitação geográfica à ação; (ii) A percepção sobre os projetos territoriais e (iii) A função do colegiado. Essas três categorias são importantes para reforçar 0 caráter condicionador das representações sociais.

No que tange às percepções sobre os projetos territoriais procuramos questionar sobre qual a intenção ao elaborar e executar um projeto no TSB e qual o foco do projeto, se está somente vinculado à questão agrícola ou tinha outro foco. Nossa intenção era perceber até que ponto as representações sobre os problemas do "rural" condicionavam a elaboração dos projetos.

Todos os depoimentos nos lavaram a entender que os projetos territoriais se enquadram em quatro eixos: Turismo, Educação, Agricultura e Agroindústria. Estes eixos foram priorizados com base nas demandas sociais, econômicas, culturais e ambientais do território. São também formas de garantir que os projetos estejam alinhados, respondam às demandas e propostas elencadas pelos atores sociais. Eles são elaborados a partir de representações sobre a realidade, sobre as necessidades de mudança, ou seja, pela visão de mundo que os atores possuem. Neste sentido, Kageyama (2008, p. 25) assume que "[...] as diferentes representações que são feitas da ruralidade têm diferentes consequências sobre as formas de desenvolvimento rural que são incentivadas ou permitidas". Assim, a própria definição destes eixos e, posteriormente, dos projetos, já caracteriza uma forma de disputa pelas formas e alternativas de desenvolvimento.

Quando questionamos os informantes sobre o que consideram um "bom projeto" as representações sociais nos dizem algo importante sobre a mudança de lócus de incidência das ações de desenvolvimento rural das políticas públicas. $\mathrm{Na}$ análise das entrevistas surgiram três categorias que tentam qualificar os "bons" projetos. De acordo com estas categorias, são "bons projetos" aqueles que: (a) possuem abrangência territorial; (b) cumprem os seus objetivos; e, por fim, os que (c) estão enraizados em demandas sociais locais e em iniciativas existentes.

Apesar das disputas e conflitos por recursos e por visões de mundo, os depoimentos apontam para uma mudança na representação sobre a delimitação geográfica para a ação no TSB, indicando a possibilidade de que a visão "municipalizada" não é mais adequada (ou desejada) aos projetos empreendidos. Essa mudança no lócus de incidência do desenvolvimento é também e, sobretudo, uma mudança nas referências que orientavam os projetos e políticas, as quais se ancoravam, principalmente, em abordagens estruturalistas, setoriais e economicistas dos processos de desenvolvimento.

Em relação à categoria "Colegiado", é perceptível a representação de que "é no colegiado que o território acontece". As dinâmicas e interações sociais para a política de desenvolvimento territorial do MDA acontecem, de fato, com maior intensidade, no colegiado. Pois é neste espaço que os conselheiros se expressam, discutem e propõem ideias e projetos. As atividades e processos fora do colegiado, relacionados à operacionalização da política são, na verdade, desdobramentos das decisões e encaminhamentos tomados em seu interior. Dessa forma, os problemas, as percepções dos problemas e as tentativas de mudanças são todas visualizadas pela interação proporcionada no bojo das atividades do colegiado. Essa 
representação condiciona inclusive a forma de funcionamento das dinâmicas internas e à importância desta estrutura formal de deliberação.

\section{CONCLUSÕES}

Todas as questões levantadas neste trabalho remetem à natureza da ação humana, mediada pelas representações sociais. Destacamos com essa abordagem uma dimensão cognitiva e simbólica do processo de interação para o desenvolvimento territorial, mostrando como as representações sociais auxiliam a análise dos processos de desenvolvimento ao desvelarem a maneira como os atores conhecem e traduzem a realidade em que intervém. A utilização das representações sociais como categoria analítica no estudo do desenvolvimento territorial atua como instrumento que possibilita entender relações estabelecidas por (e dentro dos) grupos, bem como as mudanças e permanências promovidas socialmente.

No caso do Território Serra do Brigadeiro, as dinâmicas de desenvolvimento traduzidas nas relações entre os diferentes atores e nas disputas por legitimação e por recursos nos imprimem representações sociais que permitem compreender os processos sociais e políticos. Os pactos entre organizações que antes eram "de lados apostos", o afastamento de algumas organizações dos processos de decisão colegiada e os conflitos entre poder público e organizações da agricultura familiar são todos processos desencadeados pela mudança de representação sobre o processo de desenvolvimento e sobre a disputa por recursos.

As representações sobre os significados do território também alteraram significativamente as ações no TSB. Como as prefeituras representam o território apenas como meio de acessar recursos públicos, na medida em que os recursos são escassos a tendência é de afastamento. No caso das organizações de agricultores familiares, que extrapolam essa visão, e percebem também as interações, o recurso, por mais que seja fundamental, não determina os processos desencadeados.

Quando analisamos a delimitação geográfica para ação, a percepção sobre o foco dos projetos e o papel do colegiado também nos direcionamos à importância das representações sociais. Os bons projetos são entendidos como aqueles que possuem foco territorial, e extrapolam o limite municipal; os projetos não possuem foco só agrícola sob a percepção de que o rural não pode ser mais só o agrícola, e o Colegiado é a estrutura formal onde se materializa o território.

Percebemos que as representações sociais possuem vínculo direto com as realidades e contextos sociais, que elas condicionam as ações dos indivíduos. Para os processos de desenvolvimento rural e territorial a interpretação das representações sociais se torna fator fundamental para aqueles que procuram estudar a natureza das dinâmicas e as mudanças sociais. Essa perspectiva de análise possibilitou, assim como era almejado, superar o caráter normativo comumente encontrado nos estudos acadêmicos sobre desenvolvimento territorial rural. Neste caso, o compreender as representações sociais desvelou elementos subjacentes à implementação formal/institucional da política. Isso fez emergir um tipo de influência pouco sinalizada no direcionamento dos resultados de políticas públicas: a dimensão cognitiva. Como visto, são as representações sociais que guiam as ações dos atores. Pela relevância da abordagem, sugere-se que futuras pesquisas invistam em recortes analíticos similares e ampliem o escopo da amostra de pesquisa. 


\section{REFERÊNCIAS}

ABRAMOVAY, R. Para uma teoria dos estudos territoriais. In: MANZANAL, M.; NEIMAN, G.; LATTUADA, M. (Org.). Desarrollo rural: Organizaciones, instituciones y territorios. Buenos Aires: Ediciones Ciccus, 2006.

ABRAMOVAY, R. O Capital Social dos territórios: repensando o desenvolvimento rural. Economia Aplicada, Ribeirão Preto, v. 4, n. 2, p. 379-397, 2000.

BARDIN, L. Análise de conteúdo. Lisboa: Edições Setenta, 2011.

BERDEGUE J.; et al. Determinantes de las dinámicas de desarrollo territorial rural em América Latina. Documento de Trabajo N¹01. Programa Dinámicas Territoriales Rurales. Santiago: Rimisp, 2011.

BOISER, S. Post-scriptum sobre desenvolvimento regional: modelos reais e modelos mentais. Planejamento e políticas públicas, Brasília, n. 19, p. 307-343, 1999.

BONNAL, P.; CAZELLA, A. A.; DELGADO, N. G. Contribuições ao estudo do desenvolvimento territorial rural: reflexões metodológicas a partir do caso brasileiro. Biblio 3W, v. 17, n. 1002, 2012.

BOURDIEU, P. Razões Práticas: sobre a teoria da ação. Campinas: Ed. Papirus, 1996.

BRANDÃO, C. Territórios com classes sociais, conflitos, decisão e poder. In. ORTEGA, A. C.; ALMEIDA FILHO, N. (orgs.), Desenvolvimento territorial: segurança alimentar e economia solidária. Campinas: Editora Alínea, 2007.

BRASIL. Ministério de Desenvolvimento Agrário (MDA). Referências para o Desenvolvimento territorial sustentável. Brasília, DF: MDA/SDT, CONDRAF, 2003.

CENTRO DE TECNOLOGIAS ALTERNATIVAS DA ZONA DA MATA (CTA-ZM). $P T D R S$ - Plano territorial de desenvolvimento rural sustentável da Serra do Brigadeiro. Viçosa: CTA-ZM, 2004.

COELHO, V. S. P.; FAVARETO, A. Dilemas da participação e desenvolvimento territorial. Revista de Desenvolvimento Econômico, v. 10, n. 18, p. 15-26, 2008.

DELGADO, N. G.; LEITE, S. P. Políticas de desenvolvimento territorial no meio rural brasileiro: novas institucionalidades e protagonismo dos atores. Dados, v. 54, n. 2, p. 431-473, 2011.

DOMINGUES, I. Epistemologia das ciências humanas - tomo 1: positivismo e hermenêutica. São Paulo: Loyla, 2004.

EISENHARDT, K. M. Building theories from case study research. Academy of Management Review, v. 14, n. 4, p. 532-550, 1989. 
FAVARETO, A. Abordagem territorial do desenvolvimento rural: mudança institucional ou "inovação por adição". Estudos Avançados, v. 24, n. 68, p. 299-319, 2010.

FAVARETO, A. S. Tendências contemporâneas dos estudos e políticas sobre desenvolvimento territorial. In: MIRANDA, C.; TIBURCIO, B. (org.) Políticas de desenvolvimento territorial rural no Brasil: avanços e desafios. Brasília: IICA, 2010

FAVARETO, A. S. Paradigmas do desenvolvimento rural em questão. 1. ed. São Paulo: Fapesp/lglu, 2007. v. 1.220 p.

FIALHO, M. A. V.; WAQUIL, P. D. O desenvolvimento rural: concepções e referências para a proposição de políticas públicas de desenvolvimento nos territórios rurais. Extensão Rural, n. 15, p. 129-165, jan-jun, 2008.

FROEHLICH, J. M.; ALVES, H. F. I. Novas identidades, novos territórios: mobilizando os recursos culturais para o desenvolvimento territorial. Extensão Rural, ano XIV, n. 15, p. 65-90, jan-dez, 2007.

GEERTZ, C. A interpretação das culturas. Rio de Janeiro: Guanabara Koogan, 1989.

GREENWOOD, E. Metodologia de la investigación social. Buenos Aires: Paidós, 1973.

HAESBAERT. R. O mito da desterritorialização: do "fim dos territórios" à multiterritorialidade. Rio de Janeiro: Bertrand Brasil, 2004.

HOROCHOVSKI, M. T. H. Representações sociais: delineamentos de uma categoria analítica. Em Tese, v. 2, n. 1, jan./jun., p. 92-106, 2004.

INSTITUTO VITUAL DE TURISMO. Boas Práticas para o turismo comunitário $2015 . \quad$ Disponível em: http://www.ivtrj.net/ivt/indice. aspx?pag=n\&id=10537\&cat=SUDESTE\%20.\%20Minas\%20Gerais\&w $\mathrm{s}=0$. Acesso em: 20 de Janeiro de 2016.

JODELET. D. Representações sociais: um domínio em expansão. In: JODELET, D. (Org.). As representações sociais. Rio de Janeiro: EDUERJ, 2001. p. 17-44.

JOHN, P. Analysing public policy. Londres: Printer, 1999.

MOSCOVICl, S. Representações sociais: investigações em psicologia social. Petrópolis: Vozes, 2003.

OLIVEIRA, M. S. B. S. de. Representações sociais e sociedades: a contribuição de Serge Moscovici. Revista Brasileira de Ciências Sociais, São Paulo, v. 19, n. 55, jun., p.180-186, 2004.

STAKE, R. E. Case Studies. In: DENZIN, Norman K.; LINCOLN, Y. S. Handbook of qualitative research. London: Sage, 1994. 
THEYS, J. O ordenamento territorial face ao desenvolvimento sustentável: sentido e limites de uma integração. Eisforia, v. 4, n. especial, p. 179-198, 2006.

TRIVIÑOS, A. N. S. Introdução à pesquisa em ciências sociais: a pesquisa qualitativa em educação. São Paulo: Atlas, 1987.

YIN, R. K. Estudo de caso: planejamento e métodos, 2. ed. Porto Alegre: Bookman, 2001. 